\title{
An Investigation of Surface Roughness in Micro-end-milling of Metals
}

\author{
Xiubing Jing ${ }^{1}$, Huaizhong $\mathrm{Li}^{2^{*}}$, Jun Wang ${ }^{3}$, Yanjie Yuan ${ }^{1}$, Dawei Zhang ${ }^{1}$,
}

Ngaiming Kwok ${ }^{3}$, Thai Nguyen ${ }^{4}$

${ }^{1}$ Key Laboratory of Mechanism Theory and Equipment Design of Ministry of Education, Tianjin University, Tianjin 300072, China

${ }^{2}$ Griffith School of Engineering, Gold Coast campus, Griffith University, QLD 4222, Australia

${ }^{3}$ School of Mechanical and Manufacturing Engineering, The University of New South Wales, Sydney, NSW 2052, Australia

${ }^{4}$ The University of Sydney, NSW 2006, Australia

* Corresponding author:

Dr Huaizhong Li, Griffith School of Engineering, Gold Coast Campus, Griffith University, QLD 4222, Australia. E-mail: lihuaizhong@gmail.com; h.l@@griffith.edu.au. Telephone: +61 (7) 5552 8252; Facsimile: +61 (7) 55528062

\section{Biographical Note for Authors:}

Xiubing Jing received her $\mathrm{PhD}$ degree in mechanical engineering from Tianjin University, Tianjin, China, in 2010. She is currently a lecture in the school of mechanical Engineering, Tianjin University, China. She has more than 15 years of teaching and research experience in the areas of metal cutting, optimisation, design and manufacturing processes. She has also published more than 10 papers in referred international journals, conference and proceedings. 
Huaizhong Li obtained a BE degree from Tsinghua University, China, ME degree from Xi'an Jiaotong University, China, and Ph.D. degree from the National University of Singapore (NUS), all in mechanical engineering. He is now a Lecturer at Griffith School of Engineering, Griffith University. He had worked as a Senior Research Engineer at Singapore Institute of Manufacturing Technology (SIMTech), an Associate Principal Engineer with Vestas Technology R\&D Singapore, and a Lecturer at UNSW Australia. His research interests span the areas of advanced manufacturing technologies, machining and micromachining of hard-to-cut materials, machine dynamics and vibration control, condition monitoring and advanced signal processing, mechatronics, etc. Dr Li has published over 70 peer reviewed technical papers in international journals and conference proceedings, and filed 2 patent applications. He is a winner of the 2015 Thatcher Bros Prize, the Institution of Mechanical Engineers (IMechE), UK.

Jun Wang received a BE degree from Dalian University of Technology in 1982 and a PhD from the University of Melbourne in 1993. He is now the Professor and Research Champion in Manufacturing Engineering at the University of New South Wales. His main research interests are in multi-length scale machining, advanced and micro-cutting tools and cutting tool materials. He has had more than 350 publications including a monograph, some 250 refereed journal articles and 23 edited books. He has been involved actively in the profession, including chairing and co-chairing 19 international conferences and serving in a large number of professional committees. Prof. Wang is the Chairman of the International Committee for Abrasive Technology, the President of the Ausinan Science and Technology Society, and a member of the Mechanical College Board of the Institution of Engineers Australia. He also serves as the Editor-in-Chief of the International Journal of Abrasive Technology, Associate Technical Editor for the Machining Science and Technology journal, Associate Editor for 
the Australian Journal of Mechanical Engineering (2008-2012), Associate Editor for the International Journal of Manufacturing Science and Technology, and Regional Editor for the Frontiers of Mechanical Engineering journal (2008-2012). He is a Fellow of the Institution of Engineers Australia and a Fellow of the International Society for Nanomanufacturing.

Yanjie Yuan is a $\mathrm{PhD}$ candidate in Mechanical Engineering. He is pursuing his $\mathrm{PhD}$ in mechanical engineering at School of Mechanical Engineering, Tianjin University. His current research interests include micro/meso scale manufacturing, micro-Machine Tools for manufacturing of precision parts. He has published severalpapers in various reputed international journals, conferences and proceedings.

Dawei Zhang is currently a professor in Department of Mechanical Engineering, Tianjin University. He received his $\mathrm{BE}$ degree and $\mathrm{PhD}$ degree in mechanical engineering from Tianjin University in 1990 and 1995, respectively. His areas of research interests include mechanical dynamics, precision engineering, and vibration active control.

Ngaiming Kwok received the MPhil degree from Hong Kong Polytechnic University, China, in 1997and PhD degree from University of Technology Sydney, Australia, in 2007. He is now a lecturer with the University of New South Wales, Australia. His research interests include image processing, intelligent computation and automatic control. Dr Kwok was the technical committee member of several international conferences. He had published over 120 journal articles and peer reviewed conference papers.

Thai Nguyen received a $\mathrm{PhD}$ degree from the University of Sydney. He has conducted extensive research on the development of advanced techniques for processing difficult-to-machine materials. He 
has been a Chief Investigator of two Discovery Projects granted from the Australian Research Council (ARC). He has received a number of research awards, including an Australian Postdoctoral Fellowship (APD), and been elected as an OZ Reader by the ARC for reviewing the grant proposals. He has registered a patent and published more than 45 articles. His h-index (Scopus) is 12. 


\title{
An Investigation of Surface Roughness in Micro-end-milling of Metals
}

\begin{abstract}
Abs tract. This paper presents an experimental study of the effects of cutting parameters of micro-end-milling process on the machined surface roughness, in order to find the optimal operation conditions for improved surface finish. Three types of metals, namely 6160 a luminum alloy, brass, and AISI 1040 steel, are used as work materials. The effect of material property on the surface roughness is investigated. It is found that under the same machining condition, the machined surface quality of aluminum alloy is the worst, while that of brass is the best. A multiple regression model for the surface roughness is developed, which includes the effects of cutting speed, feedrate, and the interaction between them. Results based on analysis of variance (ANOVA) show that the cutting speed is the most significant factor on surface roughness. The residual analys is indicates that the multiple regression model is valid and agrees with the experimental results.
\end{abstract}

Keywords: micro-end-milling; surface roughness; cutting parameters; machining.

\section{Introduction}

Micro-milling can be used to efficiently fabricate accurate geometrical features on various materials including steel, aluminium, brass, plastics, ceramics, and many others (Syahputra and Ko 2013). However, micro-milling, typically within $1000 \mu \mathrm{m}$ in the dimension of part geometrical features, may encounter several problems related to size effects, minimum chip thickness, poor surface quality, severe burr formation, chatter, tool failure, etc. (Gilbin et al. 2013). Surface roughness is a widely used measure of surface quality, and imposes one of the most critical constraints for production efficiency and process optimization. There have been some research efforts on investigating the surface roughness in micro-end-milling. 
Yuan, Zhou and Dong (1996) studied the effect of micro tool cutting edge radius on the surface roughness in the micro-milling process and found that larger cutting edge radius would make the surface rougher due to the existence of the minimum chip thickness. Weule, Huntrup, and Tritschler (2001) investigated surface generation in micro-end-milling of steel and concluded that the surface roughness has an increasing trend when the feed per tooth is smaller than the cutting edge radius. Vogler, DeVor, and Kapoor (2004) made an attempt to explicitly apply the minimum chip thickness concept in modeling the surface generation of the micro-end-milling. They formulated the relationship between the feedrate and the surface roughness for single-phase materials and revealed the existence of an optimal feedrate in terms of the surface roughness due to the trade-off between the conventional feedrate effect and minimum chip thickness effect. Wang, Kweon, and Yang (2005) found that the surface roughness increased linearly with increases in tool diameter and spindle speed, and that the feedrate played an important role when the other parameters were constant by micro milling brass on a miniaturized machine tool. Filiz et al. (2007) investigated micro machinability of Oxygen-Free High Conductivity (OFHC) pure copper (101) in terms of surface roughness. They concluded that for low feedrates, the surface roughness at the bottoms of the channels have little variation with feedrate and spindle speed. For higher feedrates, the surface roughness increases due to the increasing dominance of the geometric effects. $\mathrm{Ng}$ et al. (2006) observed that the machined surface with an undeformed chip thickness smaller than the edge radius of the tool was rougher than at larger undeformed chip thicknesses for both low and high cutting speeds. Liu, DeVor, and Kapoor (2007) developed a surface generation model for prediction of the side wall and floor surface of micro end milling, which included a 
deterministic/geometric component from the process geometry and a stochastic component from the ploughing related phenomena. Wang et al. (2008) reported that the physical characteristics of different metal phase grains, specifically the friction coefficient and elastic modulus, are very critical to the surface generation.

Despite the large volume of research on surface roughness of micromachining, it is noticed that the effects of cutting condition parameters and work material properties in micro end milling are still not well understood. Further research is required to address the issues. This paper presents an experimental study on the variation of the resultant surface roughness related to cutting parameters and different work material in micro end-milling operations. Experiments were conducted using full factorial method to investigate the influences of the cutting parameters including cutting speed and feed per tooth. A mathematical model using the response surface method (RSM) was developed and a multiple regression model was assessed using analyses of variance (ANOVA).

\section{Experimental Setup}

A DMG 60P 5-axis CNC machining center was used to perform the micro-end milling experiments. Three different types of work materials, namely Aluminum 6061, 360 Brass (free machining brass), and AISI 1040 were used. Mechanical properties of the three materials are shown in Table 1 . The cutters used were carbide two-flute flat end micro mills with diameters of $600 \mu \mathrm{m}$ and $900 \mu \mathrm{m}$ respectively. Feedrate, cutting speed, and depth of cut are the most influential cutting parameters on surface roughness (Fuh and Wu 1995). The cutting speed, which was found to have insignificant influence on burr formation (Chern and 
Dornfeld 1996), was determined from the spindle speed and the tool diameter. In this experiment, depth of cut was fixed at $50 \mu \mathrm{m}$. It has been shown by Wang, Kweon, and Yang (2005) that the influence of depth of cut on surface roughness in micro-milling is insignificant. Four spindle speeds from $10000 \mathrm{rpm}$ to $16000 \mathrm{rpm}$ were chosen. There were also four settings for the feed per tooth. The cutting parameters used are listed in Table 2. [Table 1 near here]; [Table 2 near here].

Values of surface roughness $(\mathrm{Ra})$ of machined samples, at the bottom of the micro-end-milled slots, were measured using a Talysurf 50 stylus tip profilometer with a straight line over the bottom surface of the machined workpiece.

\section{Results and Discussion}

\subsection{The Effects of Tool Diameter and Work Materials}

Surface roughness $\mathrm{Ra}$ is the main indicator of surface quality on machined parts. The ranges of Ra based on the categories of tool diameter and work materials were summarized in Fig. 1 . In general, the smaller the value of Ra is, the better the surface quality. It can be observed that the cutter diameter has a significant influence on the surface roughness in Fig.1. The tool with $0.9 \mathrm{~mm}$ diameter achieved smaller Ra on all materials than that for the tool with $0.6 \mathrm{~mm}$ diameter. The result of Ra vs. tool diameter for $\mathrm{Al}$ is shown in Fig. 2 with 16000 rpm spindle speed to illustrate the influence of tool diameters on the surface roughness. It is clear that the $0.9 \mathrm{~mm}$ tool achieved better surface quality than that by the $0.6 \mathrm{~mm}$ tool. The same phenomenon can be seen for other materials in Fig. 1. Since the stiffness of the tool with a 
smaller diameter is lower, the tool deflection becomes more significant, and tool vibration is also more serious in micro end milling, which results in a poor surface quality.

On the other hand, the Ra was influenced by the property of materials, as shown in Fig.1. Variation of Ra for different materials is shown in Fig. 3 with the $0.9 \mathrm{~mm}$ diameter tool with the same cutting parameters to illustrate the effect of material property on the surface roughness. It can be observed that the workpiece of $\mathrm{Al}$ resulted in the worst surface roughness, and the workpiece of brass resulted in the best Ra among the three types of materials (also shown in Fig.1). Examples of the measured surface profiles for different materials are shown in Fig.4 to illustrate the two-dimensional topographies of surface roughness after machining. The values of Rz for the materials of Al, Brass and AISI 1040 are $0.5912 \mu \mathrm{m}, 0.2276 \mu \mathrm{m}$, and $0.4808 \mu \mathrm{m}$, respectively. The phenomenon is related to the material property. It is clear from Table 1 that the elastic modulus, yield strength and the hardness of Aluminum 6061 are the smallest in the three materials used; the elastic deformation of Aluminum 6061 is the largest, so the surface roughness is worse than that for brass and steel in micro end milling.

In cutting operations, the energy consumed by shear deformation and the friction between the tool and workpiece are converted into cutting heat that can lead to the temperature increase of workpiece material in the cutting zone. Workpiece material in the cutting zone is subjected to high temperature and pressure to cause a complete plasticization. One of the factors that deteriorate the machined surface is the material side flow in micro milling. Side flow is defined as displacement of workpiece material in a direction opposite to the feed direction such that burrs form on the feed mark ridges (Pekelharing and Gieszen 
1971). It is observed by Kishawy and Elbestawi (1999) that chip material flow in a direction perpendicular to that of the usual chip flow during the machining of hardened steel. This material sticks on the new machined surface and causes a deterioration of the machined surface quality, even if the surface roughness is kept within the desired tolerance. In addition, the adhered material is hard and abrasive, such that it abrades any surface that comes into contact with the machined surface. Based on the study by Sata and Shaw (1966), the influence of material side flow on surface finish and found that this component of roughness is zero for a brittle material such as brass, but may contribute up to $6 \mu \mathrm{m}$ to the roughness when alloy steel is machined.

\subsection{The Effects of Feed}

The influence of feed per tooth with the $0.9 \mathrm{~mm}$ diameter cutter on the machined surface roughness is illustrated in Fig. 5. When the feed per tooth was greater than $1 \mu \mathrm{m}, \mathrm{Ra}$ increased with the increment of feed per tooth. However, when the feed per tooth was smaller than $1 \mu \mathrm{m}, \mathrm{Ra}$ increased with the decrement of the feed per tooth. This indicates that $\mathrm{Ra}$ at low feed per tooth is affected by the geometric effect, and the phenomenon of minimum uncut chip thickness, ploughing and elastic recovery occurred in micro end milling. At a very small feed per tooth, the effective rake angle becomes negative. Elastic recovery will be generated on the machined surface. On the other hand, the shearing effect becomes more dominant when cutting at high feed per tooth. The findings are comparable to reported results by Kim, Mayor, and Ni (2004) where the minimum chip thickness should be $30 \%$ of the cutting edge radius by means of MD simulations and experiments. The minimum chip 
thickness of micro-cutting was believed to be about $25 \%$ of the cutting edge radius through a FEM study in (Jing et al. 2014). Fig. 6 shows pictures of the micro mill captured by using a microscope. The tool edge radius for the $0.9 \mathrm{~mm}$ diameter cutter used was determined as approximately $4 \mu \mathrm{m}$. It was estimated from the result that the minimum chip thickness was approximately $1 \mu \mathrm{m}$ in this case.

\subsection{The effects of Cutting Speed}

The influence of cutting speed on the Ra can be observed from Fig. 7. Under the same feed per tooth, the Ra values showed an increasing trend at high cutting speed range. This can be explained by the fact that as the cutting speed increased, the spindle speed was higher, which generated higher vibration, and the quality of surface becomes worse. It can also be seen from Fig. 7 that greater roughness values were obtained at lower cutting speeds for $\mathrm{Al}$ and Brass. This could be attributed to the occurrence of built-up-edge. The built-up edges consist of highly deformed material from the workpiece, which is bonded on the rake face and cutting edge of the cutting tool. The built-up edge is extremely strain hardened and can grow up to a noticeable size and replace the cutting tool itself to perform the actual cutting (Trent and Wright 2000). Chips tend to weld themselves to the cutting tool when working at low speed ranges. Such behaviour probably causes a poor surface finish when machining at a low cutting speed (Mufioz-Escalona and Cassier 1998).

However, the above mentioned phenomenon that greater Ra was obtained at lower cutting speeds is not obvious for steel. The Ra of steel increased with the cutting speed under the same feed per tooth. This is because that the material properties influence notably the 
built-up edge formation. The lower thermal conductivity can result in higher cutting temperature. When the cutting temperature rises to a level which causes the recrystallization of the highly strain-hardened material of the built-up edge, the hardness is lowered and the built-up edge is eliminated accordingly (Akasawa et al. 2004). The thermal conductivity of steel is the minimum among the three materials, so the built-up edge is the least for steel in micro end milling process. In Fig. 8, the chips weld to the used cutting tool is shown. For the steel workpiece, the least of chips on the cutting tool can be observed; the most of chips on cutting tool is for $\mathrm{Al}$ workpiece.

\section{Regression Modelling}

\subsection{Multiple Regression Model}

In order to predict the Ra in micro-end milling, mathematical models were developed using response surface method (RSM). The method of RSM adopts both mathematical and statistical techniques which are useful for the modelling and analysis of problems where a response of interest is influenced by several variables and the objective is to optimize the response. Usually, when the response function is not known or non-linear, a second-order model is utilized. Based on RSM, the response surface representing the surface roughness can be expressed as function of cutting parameters. The relationship between the surface roughness and machining parameters is given as follows:

$\mathrm{R}_{\mathrm{a}}=\beta_{0}+\beta_{1} \times f_{\mathrm{t}}+\beta_{2} \times v+\beta_{11} \times f_{t}^{2}+\beta_{22} \times v^{2}+\beta_{12} \times f_{\mathrm{t}} \times v$ 
where $\beta_{0}, \beta_{1}, \beta_{2}, \beta_{11}, \beta_{22}, \beta_{12}$ are regression coefficients, and can be determined using the experimental data. Then, the multiple regression model was analyzed using ANOVA.

Table 3 presents the regression coefficients estimated. All the standard error values of these coefficients are very small; it means that the model of surface roughness is estimated with confidence. Surface roughness with $0.9 \mathrm{~mm}$ diameter tool has also been analyzed by ANOVA to determine the effect of the cutting parameters on the surface roughness, as shown in Table 4. From Table 4, it can be appreciated that the P-value is less than 0.05 which means that the model is significant at 95\% confidence level. By checking the Mean Squares (MS) in Table 4, it is clearly seen that cutting speed is the most dominating factor on surface roughness, with feed per tooth the second most influential factor and feed per tooth $\times$ cutting speed is the least effective factor.

[Table 3 near here]; [Table 4 near here].

\subsection{Model Verification}

Based on ANOVA, another residual analysis is necessary to confirm that the multiple regression model is correct and the experimental results are adequately predicted by the model. The ANOVA and the F-ratio test have been performed. Table 5 presents the ANOVA results for the multiple regression model proposed for Ra given in Eq. (1). It can be appreciated that the P-value is less than 0.05 which means that the model is significant at 95\% confidence level. Also the calculated value of $\mathrm{F}_{\text {calculated }}$ is more than the standard value of the $\mathrm{F}_{0.05}$ for Ra. It means that the model is adequate at $95 \%$ confidence level to represent 
the relationship between the machining surface roughness and the cutting parameters in the micro milling process.

\section{[Table 5 near here].}

\section{Conclusions}

An experimental study on surface roughness in micro-end-milling of three metals under different cutting conditions was presented. RSM and ANONA were conducted to investigate the factors affecting the surface roughness. The effects of cutting speed, feed per tooth, as well as material property were studied. The following conclusions can be drawn:

1. The surface roughness is influenced by the cutting parameters and also the minimum chip thickness. When the feed per tooth is greater than the minimum chip thickness, surface roughness increases with the feed, otherwise, decreasing of feed will cause surface roughness to increase.

2. Cutting using the $0.9 \mathrm{~mm}$ micro-mill achieved better surface quality on all materials than that with the $0.6 \mathrm{~mm}$ tool. The surface roughness with brass was the best among the three materials tested.

3. Surface roughness models in terms of cutting parameters have been developed based on RSM. Cutting speed is found to be the most significant factor affecting surface roughness, while feed per tooth is the second influential factor. 


\section{Acknowledgements}

The first author would like to thank the support by the National Youth Foundation of China under Grant No. 51105270. The experimental work was primarily undertaken at UNSW Australia.

\section{References}

Akasawa, T., Fukuda, I., Nakamura, K., and Tanaka, T. 2004. "Effect of microstructure and hardness on the machinability of medium-carbon chrome-molybdenum steel," Journal of Materials Processing Technology, 153-154(11): 48-53.

Chern, G.L., and Dornfeld, D.A. 1996. "Burr/breakout model development and experimental verification," Journal of Engineering Material and Technology, 118 (2): 201-206.

Filiz, S., Conley, C.M., Wasserman, M.B., and Ozdoganlar, O.B. 2007. “An experimental investigation of micro-machinability of copper 101 using tungsten carbide micro-endmills," International Journal of Machine Tools and Manufacture, 47 (7): 1088-1100.

Fuh, K.H., and Wu, C.F. 1995. “A proposed statistical model for surface quality prediction in end-milling of Al alloy,” International Journal of Machine Tools and Manufacture, 35 (8): 1187- 1200.

Gilbin, A., Fontaine, M., Michel, G., Thibaud, S., and Picard, P. 2013. "Capability of 
Tungsten Carbide Micro-mills to Machine Hardened Tool Steel,” International Journal of Precision Engineering and Manufacturing, 14 (1): 23-28.

Jing, X.B., Li, H.Z., Wang, J., and Tian, Y.L. 2014. "Modelling the cutting forces in micro-end-milling using a hybrid approach," International Journal of Advanced Manufacturing Technology, 73 (9):1647-1656.

Kim, C.J., Mayor, J. R., and Ni, J. 2004. “A static model of chip formation in micro scale milling,” Journal of Manufacturing Science and Engineering, 126 (4):710-718.

Kishawy, H.A., and Elbestawi, M.A. 1999. "Effects of process parameters on material side flow during hard turning," International Journal of Machine Tool and Manufacture, 39 (7): 1017-1030.

Liu, X., DeVor, R.E., and Kapoor, S.G. 2007. "Model-based analysis of the surface generation in microendmilling-Part I: Model Development," Journal of Manufacturing Science and Engineering, 129 (3):453-460.

Mufioz-Escalona, P., and Cassier, Z. 1998. "Influence of the critical cutting speed on the surface finish of turned steel,” WEAR, 218 (1): 103-109.

Ng, C., Melkote, S., Rahman, M., and Kumar, A. 2006. “Experimental study of microand nano-scale cutting of aluminum 7075-T6," International Journal of Machine Tools and Manufacture, 46 (9): 929-936.

Pekelharing, A.J., and Gieszen, C.A. 1971. "Material side flow in finish turning," Annals of the CIRP, 20 (1): 21-22. 
Sata, T., and Shaw, M.C. 1966. "The plastic behavior of cellular materials," International Journal of Mechanical Sciences, 12 (7): 469-478.

Syahputra, H.P., and Ko, T.J. 2013. “Application of Image Processing to Micro-milling Process for Surface Texturing," International Journal of Precision Engineering and Manufacturing, 14 (9): 1507-1512.

Trent, E.M. and Wright, P.K. 2000. Metal cutting, 4th edn, Butterworth Heinemann, Boston.

Vogler, M.P., Devor, R.E., and Kapoor, S.G. 2004. "On the modeling and analysis of machining performance in micro endmilling: Part I: Surface generation,” Journal of Manufacturing Science and Engineering, 126 (4):685-694.

Wang J. S., Gong Y. D., Abba G., Chen K., Shi J.S., and Cai G.Q. 2008. "Surface Generation Analysis in Micro End-Milling Considering the Influences of Grain,” Microsystem Technologies, 14 (7): 937-942.

Wang, W., Kweon, S.H., and Yang, S.H. 2005. “A study on roughness of the micro-end-milled surface produced by a miniatured machine tool," Journal of Materials Processing Technology, 162-163(5):702-708.

Weule, H., Huntrup, V., and Tritschler, H. 2001. "Micro cutting of steel to meet new requirements in miniaturization,” CIRP Annals - Manufacturing Technology, 50 (1): 61-64.

Yuan, Z.J., Zhou, M., and Dong, S. 1996. "Effect of diamond tool sharpness on minimum cutting thickness and cutting surface integrity in ultraprecision machining," 
Journal of Materials Processing Technology, 62 (4): 327-300. 


\section{Tables with captions}

Table 1. Mechanical property of the work material

\begin{tabular}{lccc}
\hline Properties & Aluminum 6061 & 360 Brass & AISI 1040 \\
\hline Elastic Modulus (GPa) & $70-90$ & $97-115$ & $140-200$ \\
\hline Tensile Strength (MPa) & 124 & 385 & 518.8 \\
\hline Yield Strength (MPa) & 55 & 310 & 30.2 \\
\hline Elongation (\%) & 22 & 25 & 200 \\
\hline Hardness (HB) & 83 & 156 & 11.3 \\
\hline Thermal Expansion $\left(10^{-6} / \mathrm{K}\right)$ & 23.6 & 20.5 & 515 \\
\hline Specific Heat Capacity (J/g-K) & 0.896 & 115 & 0.386 \\
\hline Thermal conductivity (W/m-K) & 180 & & 51.9 \\
\hline
\end{tabular}

Table 2. Cutting conditions for micro-end-milling tests

\begin{tabular}{lll}
\hline Cutting Parameters & Symbol (unit) & Values \\
\hline Diameter of cutter & $\mathrm{D}(\mathrm{mm})$ & $0.6,0.9$ \\
\hline Depth of cut & $a_{\mathrm{p}}(\mu \mathrm{m})$ & 50 \\
\hline Spindle speed & $n(\mathrm{rpm})$ & $10000,12000,14000,16000$ \\
\hline Cutting speed (for $0.6 \mathrm{~mm}$ cutter) & $v(\mathrm{~m} / \mathrm{min})$ & $18.84,22.62,26.39,30.16$ \\
\hline Cutting speed (for $0.9 \mathrm{~mm}$ cutter) & $v(\mathrm{~m} / \mathrm{min})$ & $28.27,33.93,39.58,45.24$ \\
\hline Feed per tooth & $f_{\mathrm{t}}(\mu \mathrm{m} / \mathrm{tooth})$ & $0.5,1,2,3$ \\
\hline
\end{tabular}


Table. 3 Parameters for the surface roughness model of micro-end milling ( $0.9 \mathrm{~mm}$ cutter).

\begin{tabular}{|c|c|c|c|c|c|}
\hline \multicolumn{2}{|c|}{ Parameters } & \multirow[t]{2}{*}{ Estimated } & \multirow[t]{2}{*}{ Std. Error } & \multicolumn{2}{|c|}{ 95\% Confidence Interval } \\
\hline & & & & Lower Bound & Upper Bound \\
\hline \multirow{3}{*}{$\beta_{0}$} & $\mathrm{Al}$ & 0.7794 & 0.2739 & 0.1690 & 1.3898 \\
\hline & Steel & 0.0675 & 0.1262 & -0.1978 & 0.3327 \\
\hline & Brass & 0.2417 & 0.0648 & 0.0974 & 0.3860 \\
\hline \multirow{3}{*}{$\beta_{1}$} & Al & -0.0892 & 0.0525 & -0.2063 & 0.0279 \\
\hline & Steel & -0.0055 & 0.0094 & -0.0254 & 0.0143 \\
\hline & Brass & 0.0117 & 0.0124 & -0.0160 & 0.0394 \\
\hline \multirow{3}{*}{$\beta_{2}$} & $\mathrm{Al}$ & -0.0400 & 0.0149 & -0.0732 & -0.0069 \\
\hline & Steel & -0.0017 & 0.0069 & -0.0162 & 0.0129 \\
\hline & Brass & -0.0138 & 0.0035 & -0.0217 & -0.0060 \\
\hline \multirow{3}{*}{$\beta_{11}$} & Al & 0.0151 & 0.0099 & -0.0068 & 0.0372 \\
\hline & Steel & -0.0002 & 0.0007 & -0.0017 & 0.0014 \\
\hline & Brass & -0.0007 & 0.0023 & -0.0059 & 0.0045 \\
\hline \multirow{3}{*}{$\beta_{22}$} & Al & 0.0006 & 0.0002 & 0.0001 & 0.0010 \\
\hline & Steel & $3.710 \mathrm{E}-5$ & 0.0001 & -0.0002 & 0.0002 \\
\hline & Brass & 0.0002 & 0.0000 & 0.0001 & 0.0003 \\
\hline \multirow{3}{*}{$\beta_{12}$} & $\mathrm{Al}$ & 0.0014 & 0.0011 & -0.0009 & 0.0038 \\
\hline & Steel & 0.0002 & 0.0002 & -0.0002 & 0.0007 \\
\hline & Brass & -0.0001 & 0.0002 & -0.0006 & 0.0005 \\
\hline
\end{tabular}


Table 4 ANOVA analysis for $\mathrm{Ra}(\mu \mathrm{m})(0.9 \mathrm{~mm}$ cutter $)$

\begin{tabular}{|c|c|c|c|c|c|c|c|c|c|}
\hline & \multicolumn{3}{|c|}{ Al } & \multicolumn{3}{c|}{ Steel } & \multicolumn{3}{c|}{ Brass } \\
\hline Source & SS & $\mathrm{df}$ & $\mathrm{MS}$ & $\mathrm{SS}$ & $\mathrm{df}$ & $\mathrm{MS}$ & $\mathrm{SS}$ & $\mathrm{df}$ & MS \\
\hline$f_{\mathrm{t}}$ & 0.005734 & 3 & 0.001911 & 0.002008 & 3 & 0.000402 & 0.000502 & 3 & 0.000167 \\
\hline$v$ & 0.021881 & 3 & 0.007294 & 0.003273 & 3 & 0.001091 & 0.002603 & 3 & 0.000868 \\
\hline$f_{\mathrm{t}} \times v$ & 0.006303 & 9 & 0.000700 & 0.002753 & 9 & 0.000184 & 0.000321 & 9 & 0.000036 \\
\hline $\begin{array}{c}\text { Corrected } \\
\text { Total }\end{array}$ & 0.033919 & 15 & & 0.008034 & 15 & & & & \\
\hline
\end{tabular}

Table 5 ANOVA results for the multiple regression model for Ra $(\mu \mathrm{m})(0.9 \mathrm{~mm}$ cutter)

\begin{tabular}{|c|c|c|c|c|c|c|c|}
\hline \multicolumn{2}{|c|}{ Source } & SS & df & MS & F calculated & F0.05 & $\mathrm{P}$ \\
\hline \multirow{3}{*}{ Regression } & $\mathrm{Al}$ & 0.212124 & 6 & 0.035354 & 54.65 & 3.22 & 0 \\
\hline & Steel & 0.109199 & 6 & 0.018200 & 84.65 & 2.66 & 0 \\
\hline & Brass & 0.029123 & 6 & 0.004854 & 131.19 & 3.22 & 0 \\
\hline \multirow{3}{*}{ Residual } & $\mathrm{Al}$ & 0.006587 & 10 & 0.000659 & & & \\
\hline & Steel & 0.003868 & 18 & 0.000215 & & & \\
\hline & Brass & 0.000368 & 10 & 0.000037 & & & \\
\hline \multirow{3}{*}{ Uncorrected } & $\mathrm{Al}$ & 0.218711 & 16 & & & & \\
\hline & Steel & 0.113067 & 24 & & & & \\
\hline & Brass & 0.029491 & 16 & & & & \\
\hline \multirow{3}{*}{ Corrected } & $\mathrm{Al}$ & 0.033919 & 15 & & & & \\
\hline & Steel & 0.008034 & 23 & & & & \\
\hline & Brass & 0.003425 & 15 & & & & \\
\hline
\end{tabular}




\section{Captions of Figures}

Fig. 1 Summarized surface roughness ranges of three materials

Fig. 2 Ra vs. tool diameter for $\mathrm{Al}$ (spindle speed=16000 rpm)

Fig. 3 Variation of Ra for different materials: (a) $v=33.93 \mathrm{~m} / \mathrm{min}$; (b) $f_{\mathrm{t}}=0.5 \mu \mathrm{m} /$ tooth

Fig. 4 Measured surface profiles for different materials ( $0.9 \mathrm{~mm}$ cutter, spindle speed=10000

rpm, $f_{\mathrm{t}}=0.5 \mu \mathrm{m} /$ tooth $)$

Fig. 5 Surface roughness vs. feed per tooth with $0.9 \mathrm{~mm}$ diameter cutter

Fig. 6 Photomicrograph of the milling tools of $0.9 \mathrm{~mm}$ diameter

Fig. 7 Surface roughness vs. cutting speed with $0.9 \mathrm{~mm}$ diameter cutter

Fig. 8 Photomicrograph of micro mill (0.9 mm cutter) with chips after machining 


\section{Figures}

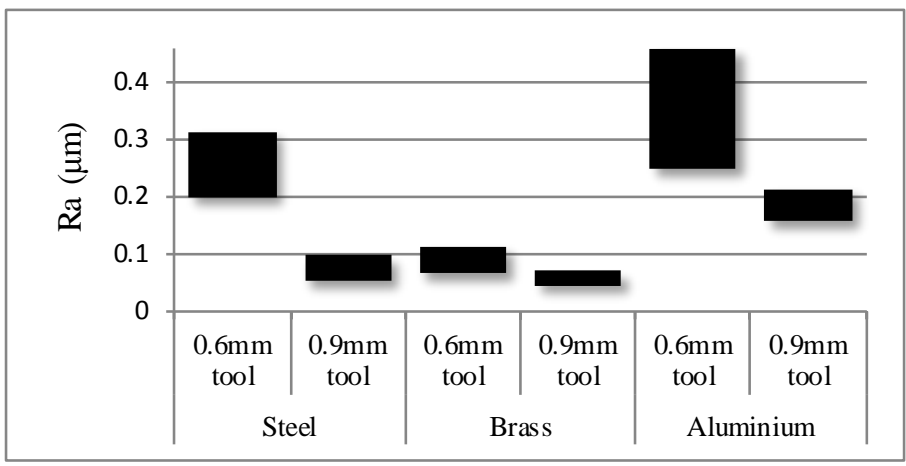

Figure 1

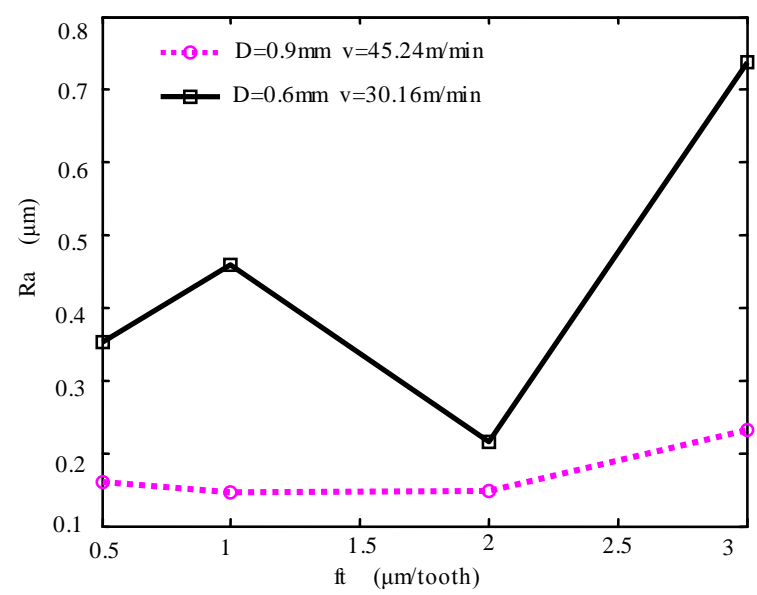

Figure 2

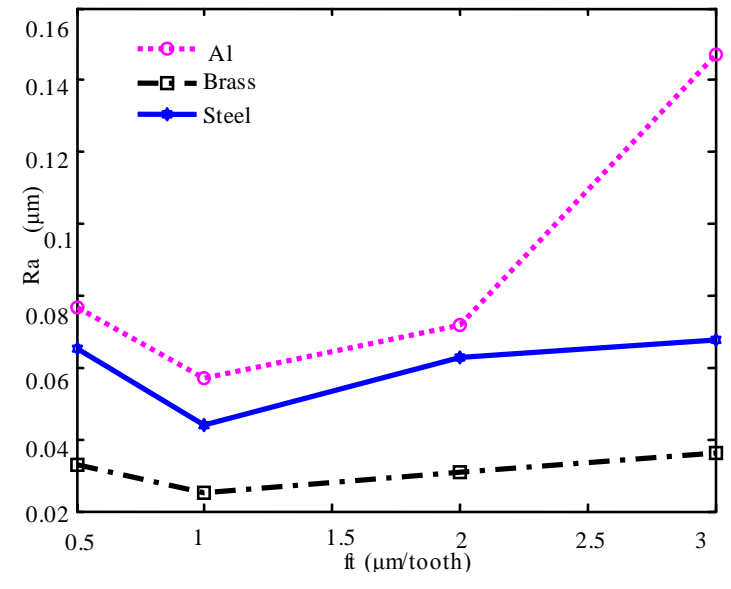

(a) $\mathrm{v}=33.93 \mathrm{~m} / \mathrm{min}$

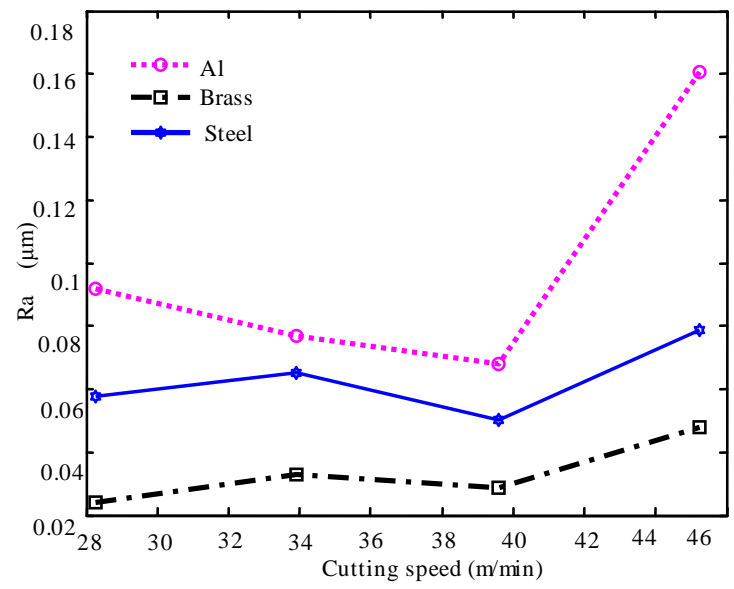

(b) $\mathrm{ft}=0.5 \mu \mathrm{m} /$ tooth

Figure 3 


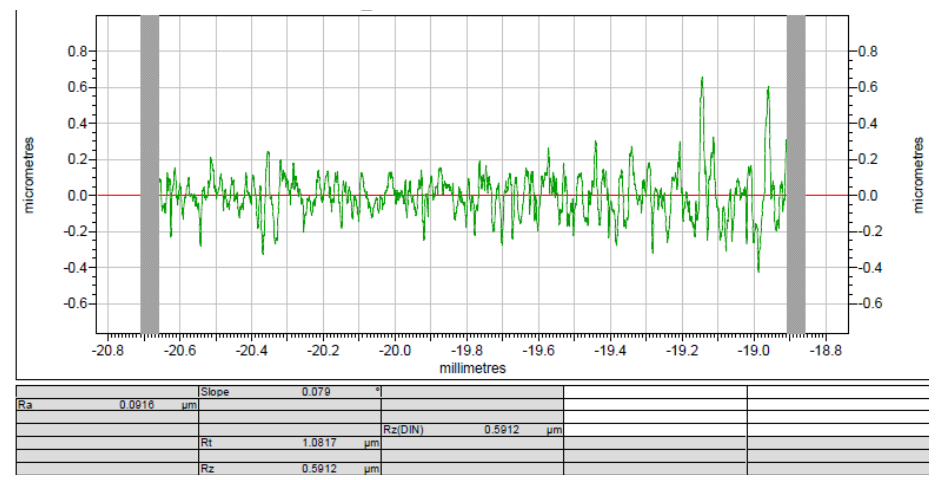

(a) $\mathrm{Al}$

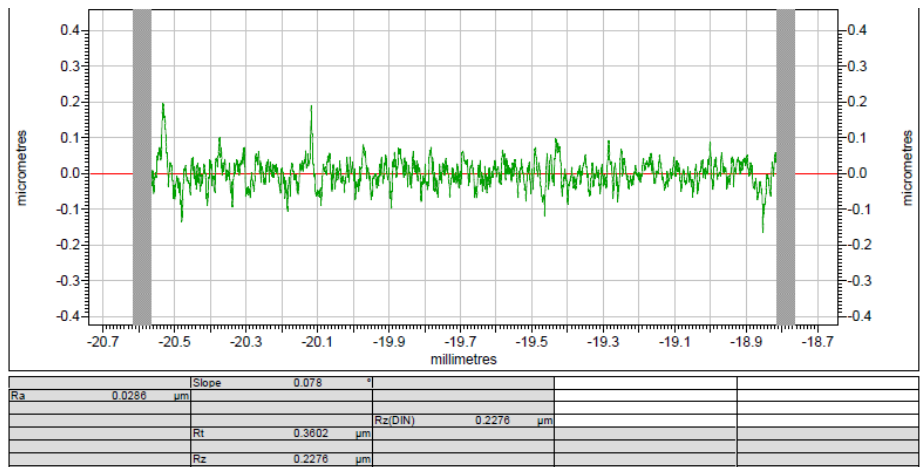

(b) Brass

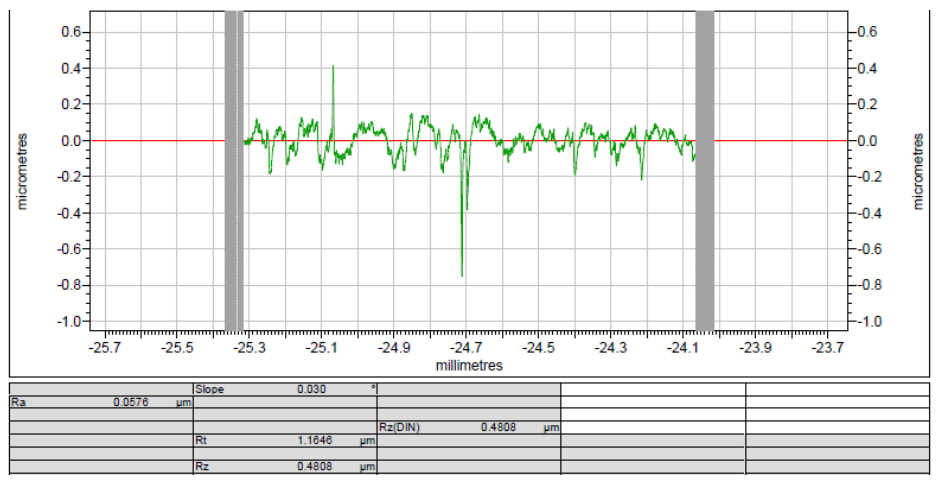

(c) AISI 1040

Figure 4 


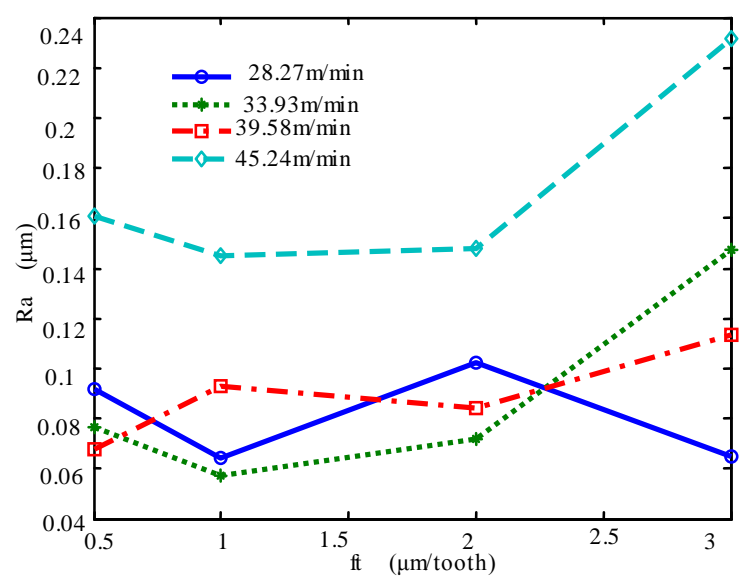

(a) $\mathrm{Al}$

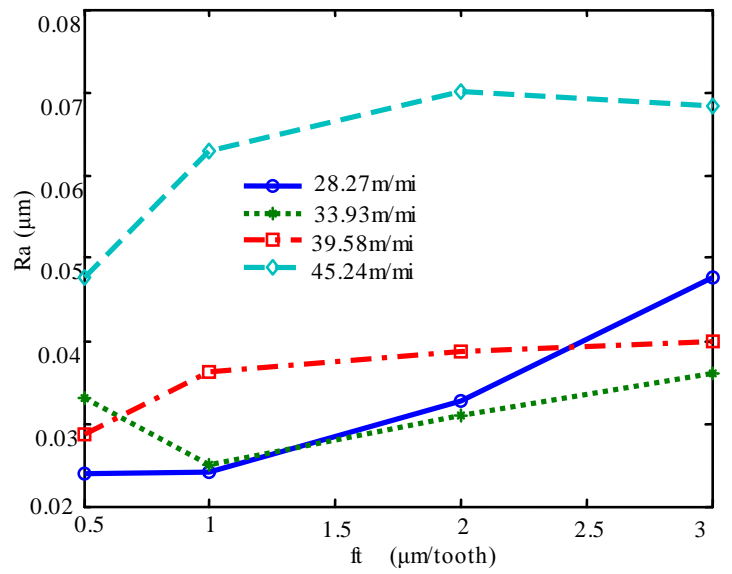

(b)Brass

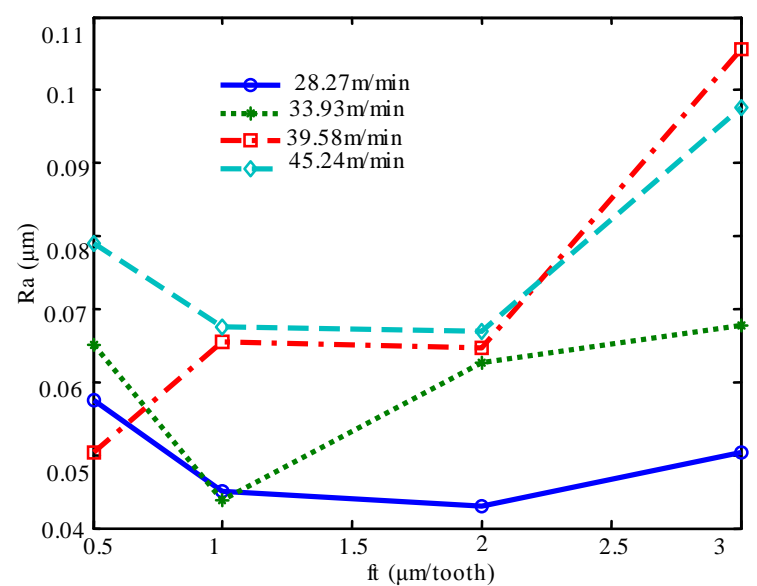

(c) AISI 1040

Figure 5 


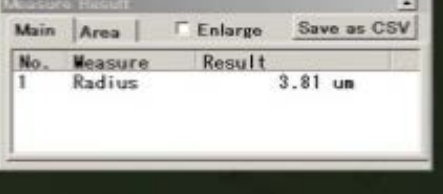

Figure 6

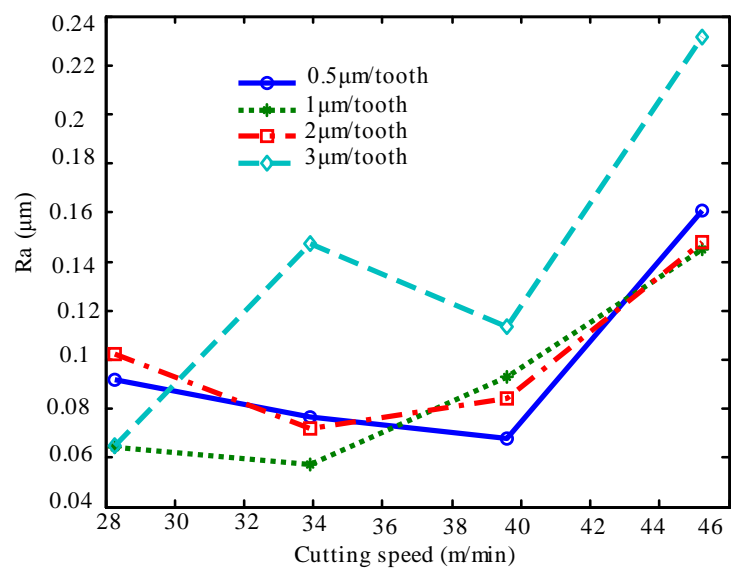

(a) $\mathrm{Al}$

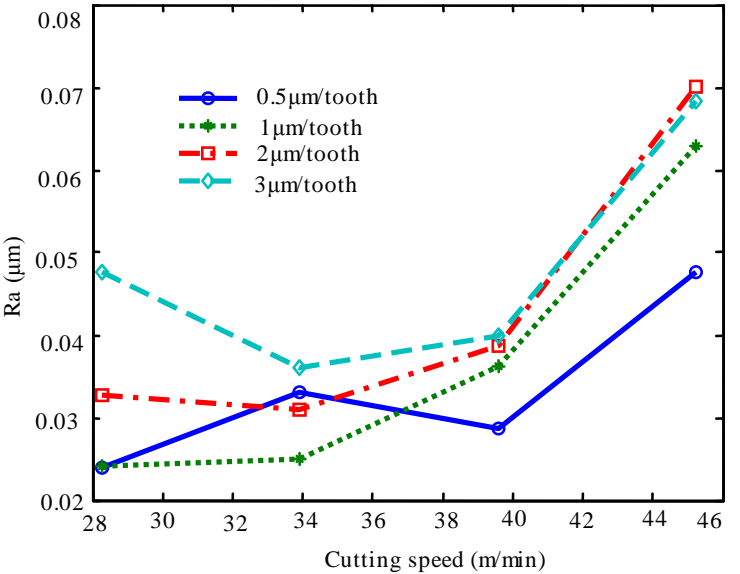

(b) Brass



(c) AISI 1040

Figure 7

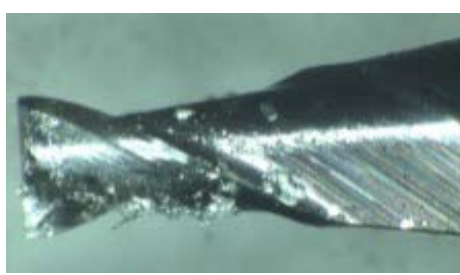

(a) $\mathrm{Al}$

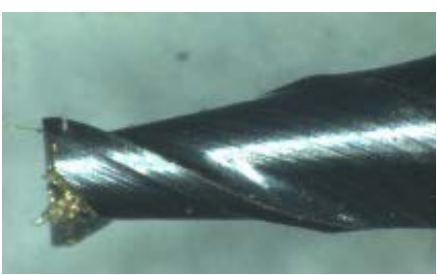

(b) Brass

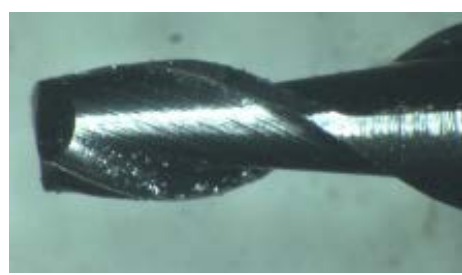

(c) AISI 1040

Figure 8 